UCRL-ID-126217

\title{
New Generation Detonics
}

\author{
P.C. Souers
}

December 15, 1996

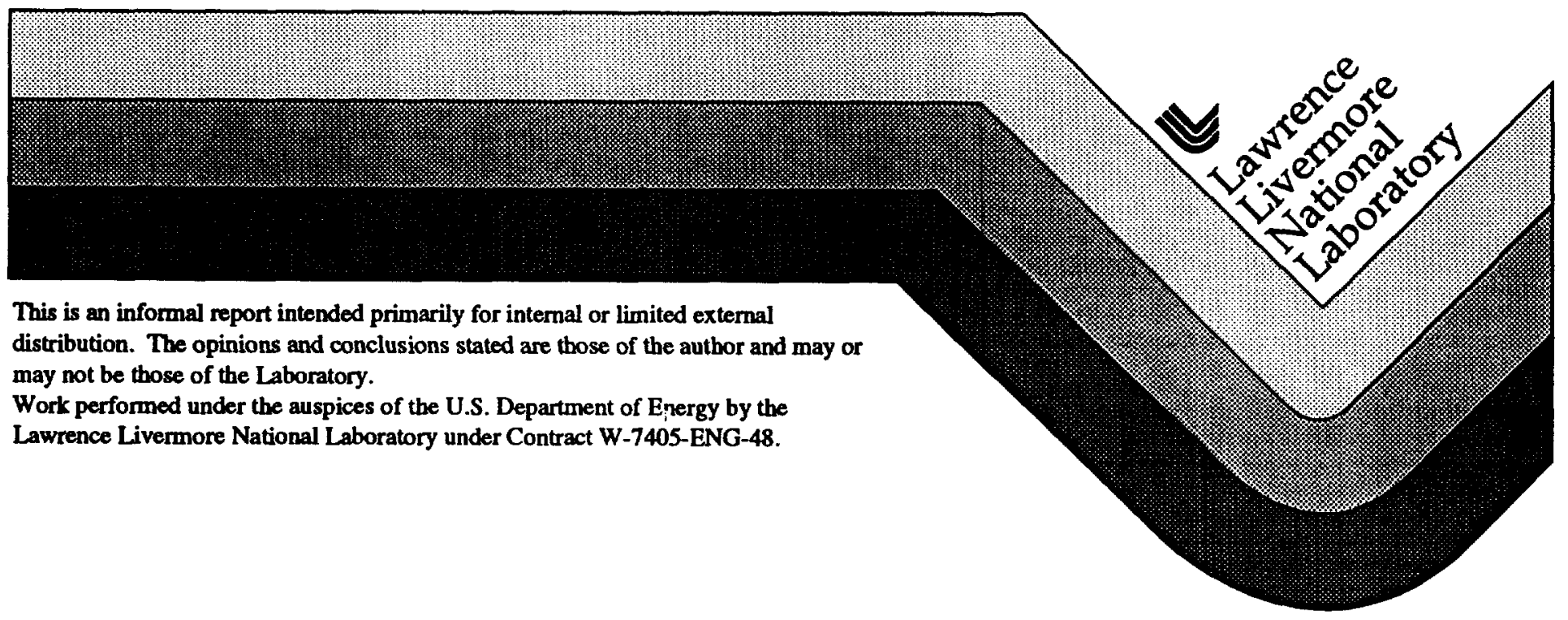




\section{DISCLAIMER}

This document was prepared as an account of work sponsored by an agency of the United States Government. Neither the United States Government nor the University of California nor any of their employees, makes any warranty, express or implied, or assumes anj legal liability or responsibility for the accuracy, completeness, or usefulness of any information, apparatus, product, or process disclosed, or represents that its use would not infringe privately owned rights. Reference herein to any specific commercial products, process, or service by trade name, trademark, manufacturer, or otherwise does not necessarily constitute or imply its endorsement, recommendation, or favoring by the United States Government or the University of California. The views and opinions of au thors expressed herein do not necessarily state or reflect those of the United States Government or the University of California, and shall not be used for advertising or product endorsement purposes.

This report has been reproduced directly from the best available copy.

Available to DOE and DOE contractors from the Office of Scientific and Technical Information P.O. Box 62, Oak Ridge, TN 37831

Prices available from (615) 576-8401, FTS 626-8401

A vailable to the public from the

National Technical Information Service

US. Department of Commerce 5285 Port Royal Rd. Springfield, VA 22161 


\section{New Generation Detonics}

\section{P. C. Souers December 15, 1996 96-DI-004 FY96 Report}

About $\$ 90$ million/year of LLNL business is connected with explosive detonation, where detonation is the chemical reaction with the maximum allowed directional energy. At the front is a thin shock wave, in which the material is compressed to $3 / 4$ of its initial volume. Behind the shock wave, the chemical reaction continues, finally losing contact with the detonation front. Even then, the reaction can produce useful work if the gaseous reaction products (up to 13 moles per original mole) are contained and the direction of expansion channeled. The energy of detonation comes either from building strain into the initial molecule (creating a more positive heat of formation) or from creating stable, low molecular weight gaseous products like water or carbon dioxide. The time scale for detonation is tens of nanoseconds and the motion of the walls driven by the explosive is in microseconds. Peak pressures are at hundreds of thousands of atmospheres and peak temperatures are thousands of degrees.

Modern theory is routinely used by drug companies to design new molecules, but it is just beginning to impact the empirical world of explosives. We have been working on the first such program, intended to substantially accelerate the development of new high performance explosive molecules. By combining state of the art quantum chemistry calculations with the aggressive synthetic pursuit of promising candidate molecules, we hope to advance the state of the art in this field by more than 50 years. As shown in Fig. 1, the energy of military explosives has risen steadily in the past two hundred years. The data base of organic compounds was, however, a few hundred in 1800 and is now millions. It has become so difficult to find the next supermolecule that a new approach is needed.

Where can this work go? If we were able to offer a truly revolutionary explosive, the level of funding in Department of Defense areas could easily increase from $\$ 1 \mathrm{M}$ to $\$ 3$ 4M. Very high performance materials could be important in future DOE explosive-driven experiments. The success of this project would also revitalize the entire LLNL explosives community, including shaped charge development and warhead design, formulation, synthesis, and theory. 


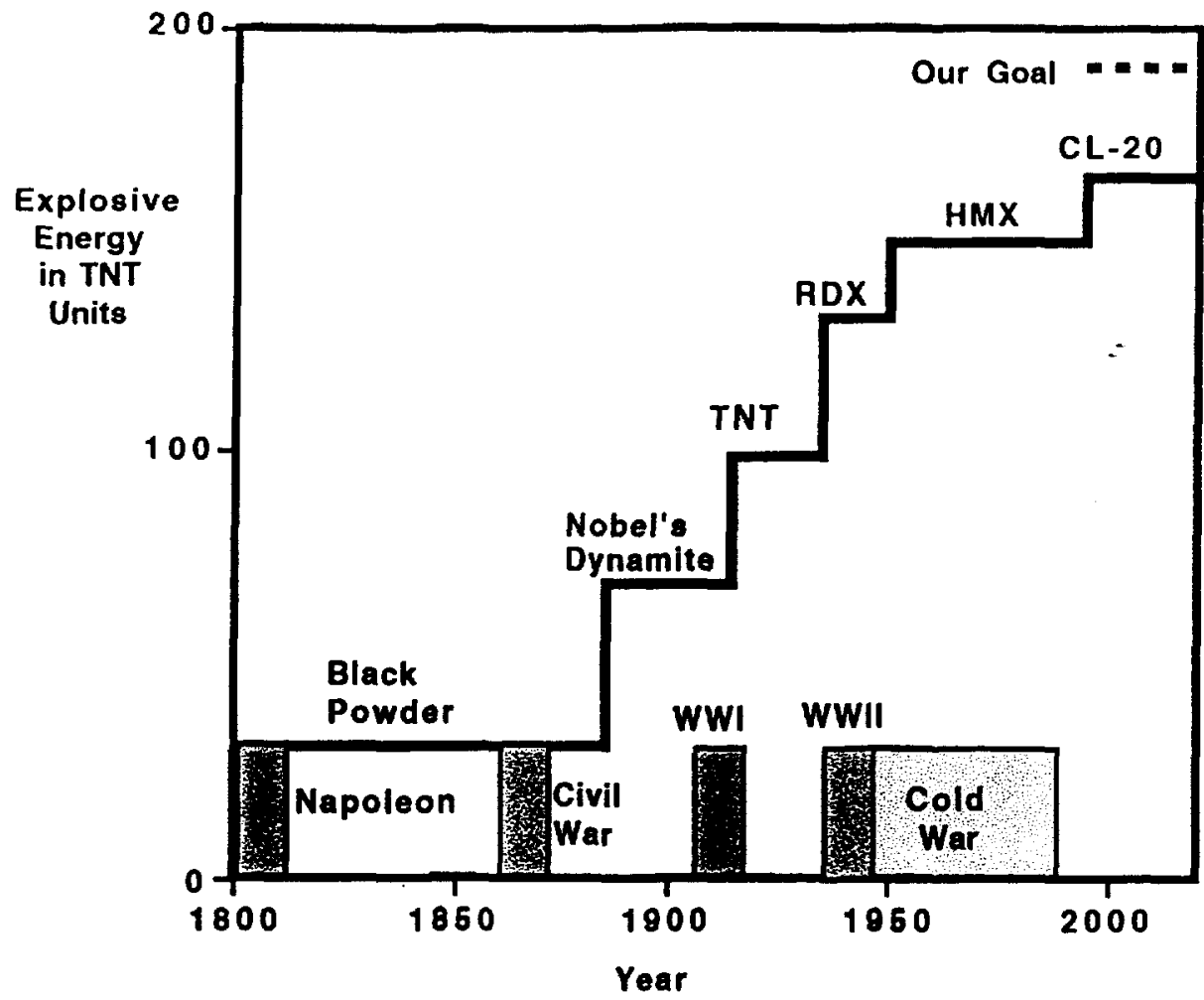

Figure 1: The evolution of military explosives. Super energy is ever harder to find.

Our approach is based on the tight linkage of theory with chemical synthesis. We have established a high explosive performance prediction code by linking the thermochemical code CHEETAH with the ab initio electronic structure code GAUSSIAN and the molecular packing code MOLPAK. GAUSSIAN is first used to determine the shape of the molecule and its binding energy. The molecules are then packed together into a low energy configuration by MOLPAK. Finally CHEETAH is used to transform the crystal energy and density into explosive performance measures such as detonation velocity, pressure, and energy. The resulting performance prediction system is diagrammed in Figure 2.

We have benchmarked our performance prediction system against a large number of known explosives of varying performance. We find that the current computational system is sufficiently accurate to distinguish between common explosives. For instance, we show in Figure 3 detonation velocities predicted by CHEETAH with theoretical and experimental densities and heats of formation. The calculated densities and heats of formation are sufficiently accurate to yield a good estimated detonation velocity. 


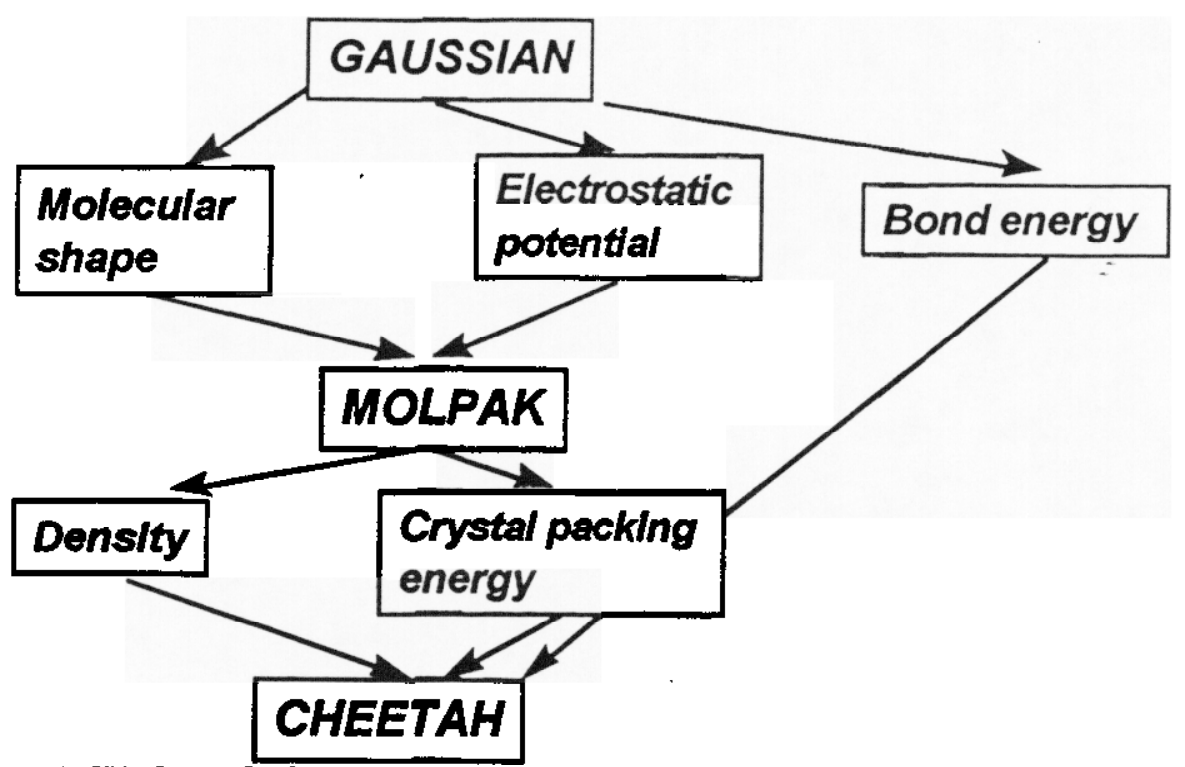

Figure 2: We have linked the above codes and properties to predict the explosive performance of new materials.

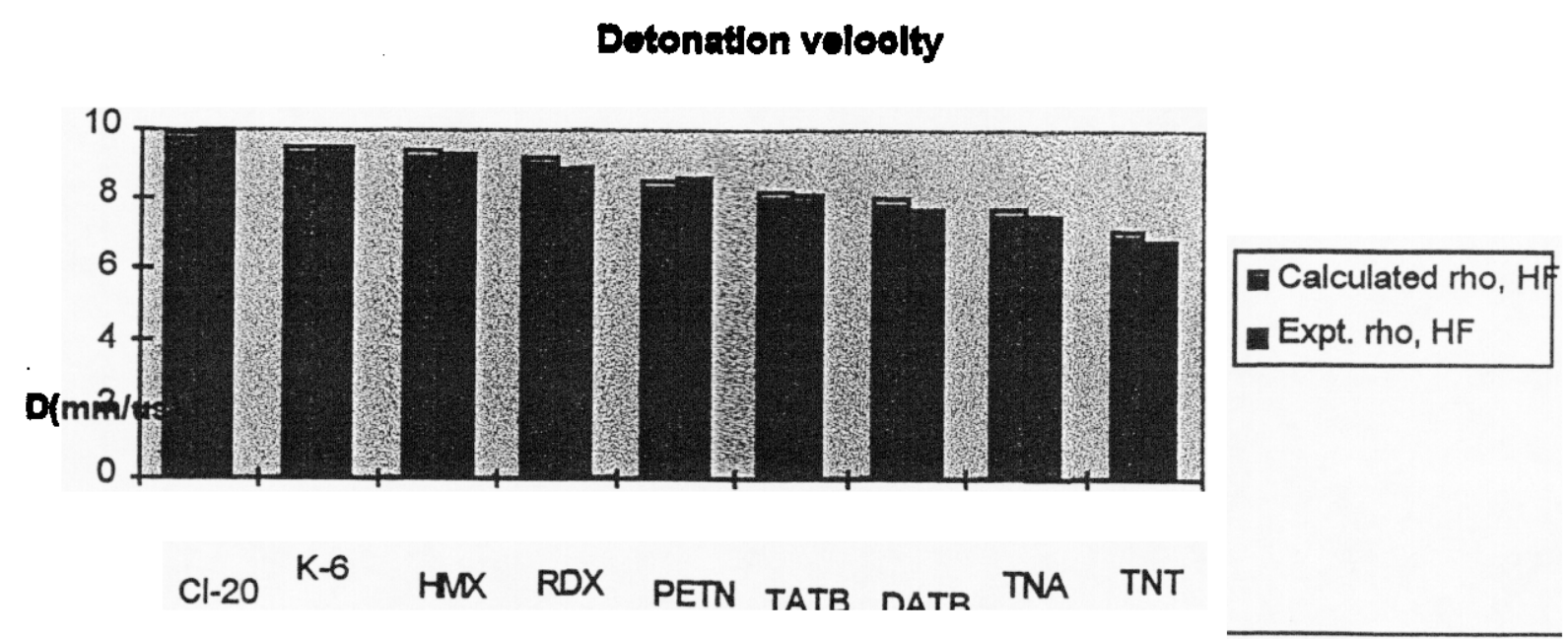

Figure 3: Detonation velocities based on predicted and experimental HE density and heat of formation are compared. 
The theoretical chemists and the organic chemists involved in this project have worked together to create over 70 target molecules. Performance calculations were then undertaken for each of the possible targets. Of the many target molecules, several showed great promise in combining performance, chemical stability, and ease of synthesis. In Figure 4, we show our first target molecule, $\mathrm{C}_{4} \mathrm{~N}_{8} \mathrm{O}_{8}$, which is currently several steps into synthesis. This molecule uses multiple chemical bonds and a bicyclic ring structure to achieve high predicted density $(2.15 \mathrm{~g} / \mathrm{cc})$ and energy $(1.4$ times HMX, the highest material in common use today). If successful, the synthesis of this material will produce the most powerful explosive known today. The proposed synthethic route is shown in Fig. 5.

Figure 4: This high performance explosive molecule is currently being synthesized. Its predicted performance is 1.4 times HMX.

We have also found molecules with higher calculated performance. A second molecule, $\mathrm{C}_{2} \mathrm{~N}_{8} \mathrm{O}_{4}$, has been identified by the computer as being 1.8 times as powerful as HMX.

In order to pursue such high performance targets, it is absolutely essential to have a reliable estimate of the molecular stability and the explosive's likely shock and impact sensitivity. An explosive molecule will only be useful if it can be handled with acceptable safety. Therefore we plan to concentrate our future theoretical efforts on sensitivity and stability prediction. 
<smiles>Brc1cn[nH]c1</smiles><smiles>Brc1cnn(-c2ccccc2)c1</smiles><smiles>O=Cc1c(Br)cnn1[P+](=O)[O-]</smiles>

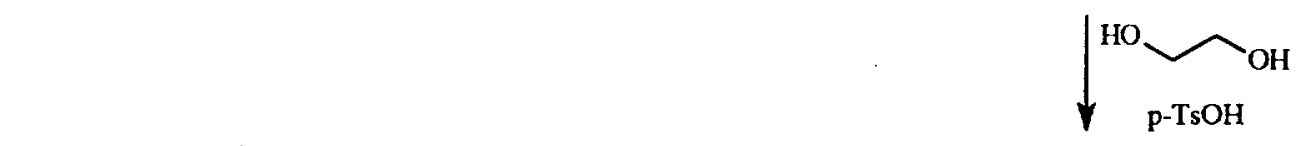<smiles>CC(C)(C)OC(=O)C[C@@H](Cn1cc(Br)c(C2OCCO2)n1)C(=O)O</smiles>

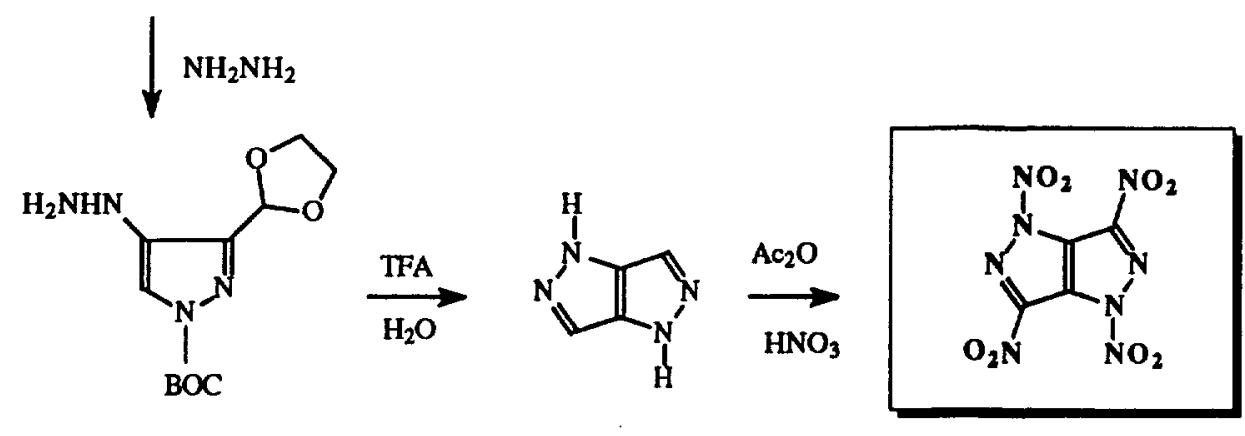

Figure 5: The proposed synthetic scheme for the molecule shown in Figure 4, $\mathrm{C}_{4} \mathrm{~N}_{8} \mathrm{O}_{8}$.

New techniques are beginning to enter into the study of detonating explosives. A detonating explosive generates a shock wave running at a high velocity and pressure. When this hits another material that is more dense, a reflected shock wave is created. By now, the explosive has broken apart into gaseous products like nitrogen and carbon dioxide, still at high pressure. The reflected shock wave, called a reshock, now further compresses and heats this gas. Theories and models exist for the initial detonation, but virtually nothing has been done about the reshock, although these occur in many explosive devices. The schematic in Fig. 6 shows an apparatus to explore reshocks. A metal impactor thrown by a gas-driven gun, hits an aluminum plate and detonates the nitromethane, a liquid, transparent explosive. The shock wave runs to the right, hitting the dense sapphire window. The reshock then travels back to the left to reverberate off the aluminum. The varied thicknesses allow reshocks to be measured at different times. Light comes out the window and its blackbody spectrum allows the temperature to be calculated. 


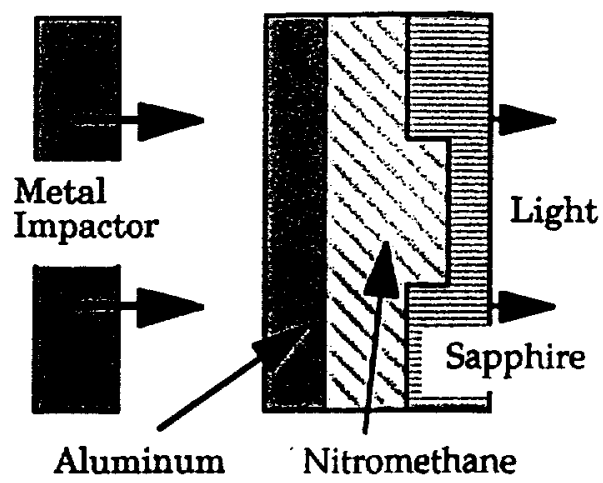

Fig. 6. Schematic of the reshock experimental apparatus.

The measured data is shown in Fig. 7. The nitromethane detonation velocity is obtained from the transit time across the sample. The temperatures are shown, with the reshock being hotter. The importance of this is in providing information that can be used to calibrate the hydrodynamic codes ("hydrocodes") used at this Laboratory. Fig. 8 shows the calculation in one dimension using a Cylinder Test equation of state for the nitromethane. The code gives the detonation pressures and velocities. The calculated velocities are too low, as compared to the experiment. So our knowledge of nitromethane did not hold up even at the starting point, when we raised the pressure above the minimum value needed for detonation. If this is the case, then the reshock properties, another step down the chain, are unlikely to be correct. Modern hydrocodes cannot deal with temperature except

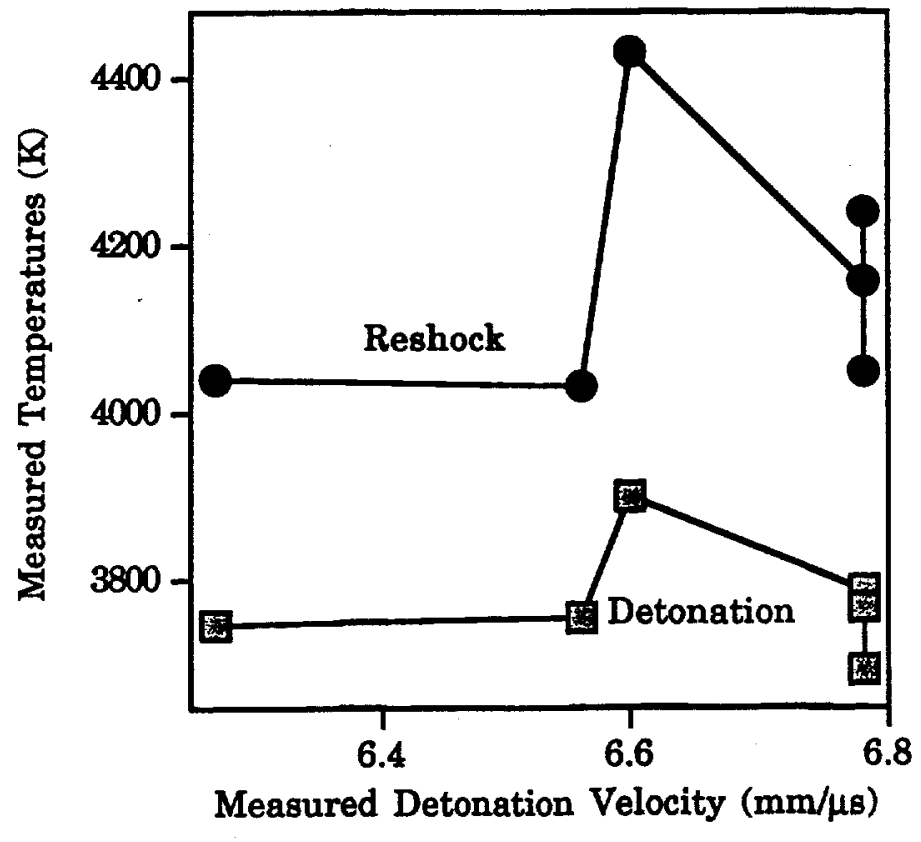

Fig. 7. The calculated nitromethane detonation velocities are low, so that the equation of state is incorrect for the overdriven state. 
in a cursory way. A thermochemical code that will be linked to a hydrocode is capable of calculating temperatures based on a library of thermodynamic data. The measured temperature will provide a check to this new code.

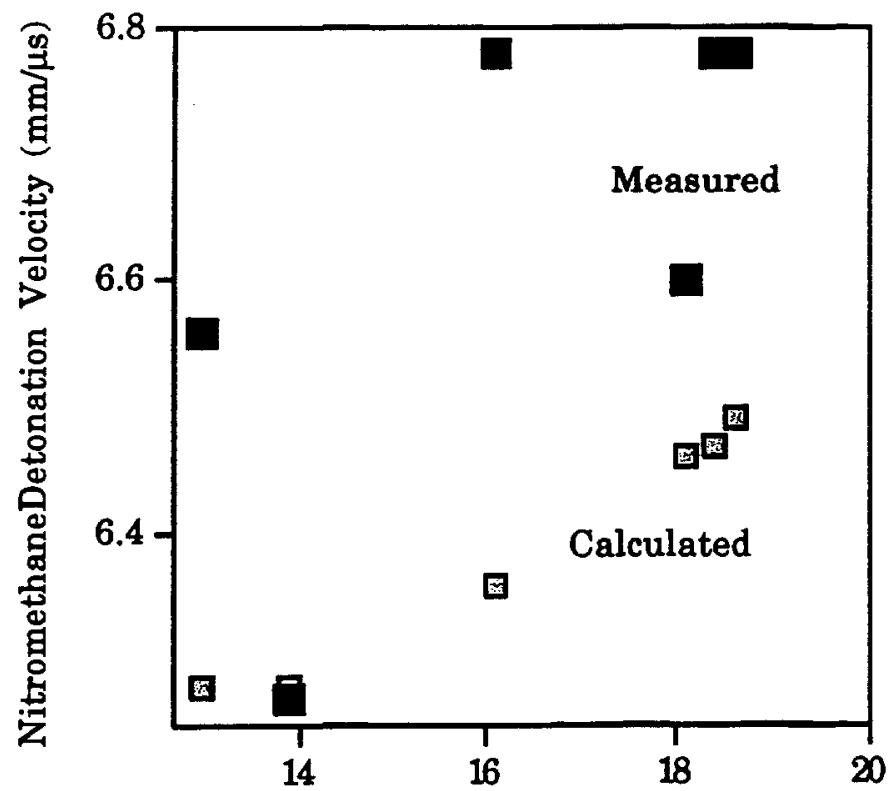

Nitromethane Detonation Pressure (GPa)

Fig. 8. Calculated and measured detonation velocities. The agreement is not good.

This is a kick-off experiment, which would hopefully lead our laboratory into modern reshock measurements. The next step is to measure the sound speed in the reshocked products as a function of distance, ie. pressure. This will lead to a total evaluation of the exisitng equations-of-state.

The sub PI's for the Energetic Material section were Laurence E. Fried, Glenn Fox, Philip Pagoria, and Christine Wu. The sub-PI for the reshock experiment was Choong-Shik Yoo.

\section{Presentations:}

L. E. Fried, "High Performance Energetio Molecules", Gordon Conference On Energetic Materials, New Hampton, NH, June, 1996.

Invited Presentations:

L. E. Fried, "LLNL Energetic Material Design Program", Office of Naval Research Workshop on Energetic Materials, Annapols, MD, December, 1996. 


\section{Publications}

C. S. Yoo, N. C. Holmes and P. C. Souers, "Detonation in Shocked Homogeneous High Explosives," Materials Research Society Symposium Proceedings, 1996, UCRL-JC121211.

\section{Manuscripts in Preparation}

C.S. Yoo, C.Souers, N.C. Holmes, "Detonation Temperature and Kinetics of Homogeneous High Explosives," J. Chem. Phys.

C.S. Yo, C. Souers, N.C. Holmes, M. van Thiel, F. Ree, "Hugoniots of Nitromethane Detonation Products", J. Phys. Chem.

C.S. Yoo, C. Souers, N. Holmes, J. Dick, "Orientational Dependence of PETN Shock Sensitivity", J. Chem. Phys. 


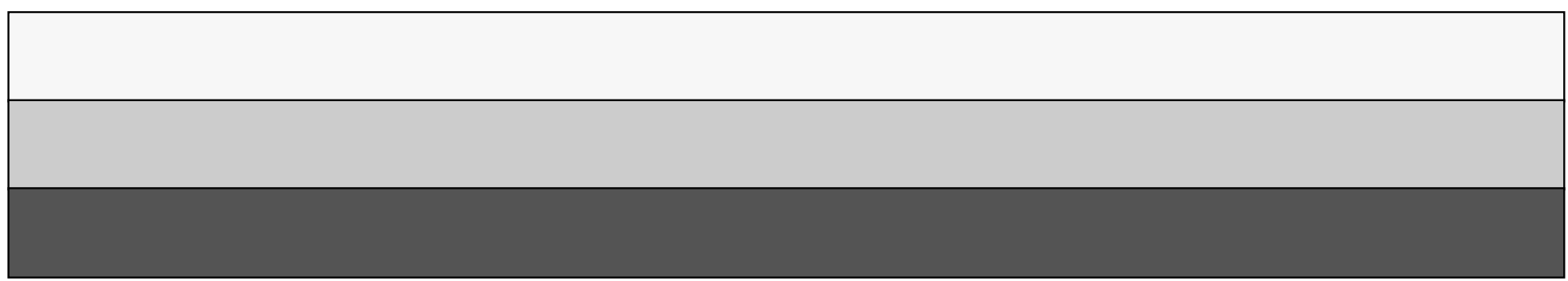

